\title{
Knowledge Sharing in Virtual Communities: A Social Exchange Theory Perspective
}

\author{
Li Jinyang \\ School of Information Management, HuBei University of Economics (China)
}

56922860@.9q.com

Received: January 2015

Accepted: March 2015

\section{Abstract:}

Purpose: The author tried to identify the knowledge sharing behaviors on the internet, using structural equation modeling methods, proposing a model based on social exchange theory in which share willingness, trust, reciprocity, altruism tended to have impact on people's knowledge sharing behaviors in virtual communities.

Design/methodology/approach: We presented an empirical research which integrated social exchange theory and structural equation modeling methods to analyze several important factors influencing members' knowledge sharing behaviors in virtual communities.

Findings: We analyzed the knowledge sharing behaviors in virtual communities. We found that members' altruism can not predict knowledge sharing behaviors. We also found that members' sharing willingness is the most important factor on virtual community knowledge sharing behaviors compared with trust, reciprocity and altruism.

Originality/value: From the perspective of social exchange theory, we did empirical test and verified the proposed research model by using structural equation modeling methods. Our finding can help recognize people's incentive about knowledge sharing.

Keywords: virtual communities, knowledge sharing, sharing behaviors 


\section{Introduction}

With the development of information technology and the prevalence of internet, the ways through which people communicate and obtain information are more and more diverse. Virtual communities emerge as a new approach for people communicate with each other and obtain information or knowledge. Online virtual communities broaden the scope of traditional communities and improve the interaction efficiency of online communication (Kim, Yu \& Lee, 2003). According to Koh and Kim (2004), virtual communities are defined as those with common objectivities or targets, engaging in knowledge sharing in virtual communities.. Social aggregation of individual relationship networks comes into being among people in virtual communities, which is composed of large, loose, geographically widespread population (Brown \& Duguid, 2001).

Previous study provided discussion about different types of elements which might have influence on people's knowledge sharing in virtual communities. A series of theories about collective action are put forwarded by Wasko and Faraj (2005) in order to identify how impetus and social investment have impact on knowledge sharing in the cyberspace. They empirically tested a knowledge sharing model and considered people tend to share knowledge if this will help promote their social status. Chiu, Hsu and Wang (2006) further developed the social capital theory and the social cognitive theory in order to build up a pattern for identifying the impetus and reason behind individual knowledge contribution in the cyberspace. A social cognitive theory was introduced by $\mathrm{Hsu}$, Ju, Yen and Chang (2007), including individual perception of knowledge sharing, expectations for individual improvement, and multidimensional trusts in order to identify people's knowledge contribution in the cyberspace. The theories of social investment and personal impetus were integrated by Chang and Chuang (2011) so as to study the influential elements about knowledge sharing on the internet. Besides, the concept of participator involvement was applied the analysis of regulating effects of personal impetus on knowledge contribution.

Judging from the knowledge management perspective, virtual communities afford a new knowledge exchange mode. Knowledge sharing activities in virtual communities were considered as a type of social exchange behavior (Fulk, Flanagin, Kalman \& Monge, 1996). Several literatures about knowledge management (Koh \& Kim, 2004; Wasko \& Faraj, 2005; Chiu et al., 2006; Hsua et al., 2007) tended to adopt quantitative or qualitative approaches to study the knowledge sharing behaviors in the virtual communities. In terms of social exchange, members in virtual communities are willing to provide valuable information and share with other members. By giving and contributing knowledge, they expect other members will give similar help in the future. Social exchange behaviors are the foundation of maintaining social interaction among people, rational individuals should pursue the biggest profit (Emerson, 1976). 
This research aims to study the motivations which have influences on individual's knowledge sharing behavior in virtual communities. On the grounds of social exchange theory, a set of assumptions was put forwarded to study how personal impetus is connected to knowledge sharing in the virtual communities.

\section{Theoretical Background and Research Model}

Social Exchange Theory is an important perspective for the study of interpersonal relationship. According to the theory, interpersonal interaction is a process. In the process, various parties conduct activities and exchange valuable resources with each other. The core of the theory is the principle of reciprocity to which the interpersonal relationship adheres. Rewards for the exchange not only include material rewards, but also psychological rewards, such as support, trust, self-esteem and prestige. In the virtual community, individuals are main subjects, who are the implementers of knowledge sharing activities. The knowledge sharing activities between individuals is the knowledge exchange between the knowledge owners and the knowledge demanders. In the perspective of social exchange theory, the knowledge sharing in the virtual communities is a personal behavior, and a kind of exchange between individuals.

In the virtual communities, individuals are the participation of knowledge sharing activities. Based on social exchange theory, we may assume that the sustainable knowledge sharing behaviors should have influence on forming a long term relationship among members. Contributions of knowledge to virtual communities cause knowledge possessors to lose their useful value and become beneficial to contributors. Therefore, people pay their effort and sacrifice their time while they could simply enjoy the efforts of other members (Wasko \& Faraj, 2005).

Knowledge sharing with other members tends to be the biggest challenge in cultivating virtual communities. Davenport and Prusak (1998) considered knowledge sharing is usually not natural. Bock, Zmud, Kim and Lee (2005) argued that people share what they knew when their interests outweigh the costs of knowledge contribution. This suggested that people consider their knowledge as useful and significant. Therefore they were suspicious of the knowledge from others.

Blau (1986) thought that the social exchange between people is originated from social attraction. Only when each party can get useful information or knowledge from the other party, the two parties will continue to cooperate with each other. Therefore, when the parties interacting with each other are confronted with various scenarios, they must adjust the resources to meet the demands of the other party to make the exchange relationship attractive to both parties. 
Thus, according to the social exchange theory, identifying the impetus of knowledge sharing behavior in virtual communities is of great significance. Regarding the knowledge sharing behaviors between members in the virtual community, this paper evaluates them from two aspects, namely member sharing willing and member sharing behaviors.

\subsection{Sharing Willingness and Sharing Behaviors}

Willingness of individuals is the probability of engaging in doing something and the best variable to predict behavior. Theory of Reasoned Action thinks that the stronger intention that individuals have for a certain behavior, the larger chances are for them to implement the behavior. The knowledge sharing willingness between members in the virtual community can help promote knowledge sharing efficiency. Positive sharing willingness can stimulate the sharing behaviors. In this paper, sharing willingness is divided into two perspectives: sharing attitude and sharing expectation.

Bock and Kim (2002)proposed that sharing attitude had a positive effect on sharing willingness. Bartol and Srivastava (2002) pointed out that the sharing expectation of the individuals participating in the knowledge sharing is an important factor influencing the knowledge sharing decision-making.

Sharing behaviors can be divided into two kinds, namely code of conduct and level of involvement. The former refers to the member behaviors in the community, which is reflected as recognition and a sense of belonging to and of the group. The latter reflects members' time and energy invested in the process of using the virtual community. In the virtual community, effective incentive mechanism can help fully guide individuals to generate their intention of knowledge sharing. Therefore, it is of vital importance to stimulate the individual sharing intention on the internet to promote knowledge sharing behaviors regarding to social exchange. Thus hypothesis 1 is as follows:

H1. Members' sharing willingness tends to affect knowledge sharing behaviors in a positive way.

Proceeding from social exchange theory, this paper analyzes and studies several important influential elements in the knowledge sharing between members through deepening the author's experience of the virtual community and interview the members with the virtual community. 


\subsection{Trust}

Trust can influence the social exchange behaviors between people. Wu and Tsang (2008) proved through empirical research that trust is closely related to the members' viscidity to the cyberspace and their willingness of knowledge sharing. Trust has great impact on participants' behaviors in the virtual community who participate in knowledge sharing. We may conclude that the knowledge sharing behaviors which establish on the basis of trust can improve members' willing to provide private resources for others and to form exchange behaviors. Different from the traditional communities, members of the virtual community are distributed in different geographic locations. For lack of face-to-face exchanges between community members, it is hard for the members to form and maintain a relationship that support each other. The relationship between participants in the virtual community is usually thought to be more vulnerable and uncertain. In the cyberspace, knowledge sharing behaviors aim to contribute knowledge, and there exists knowledge asymmetry between the knowledge demander and knowledge owners. Knowledge asymmetry is reflected as: on one hand, knowledge owners may be not willing to publicize their knowledge due to various reasons; on the other hand, the authenticity of the knowledge influences knowledge sharing. Therefore, the trust relationship between participants in the virtual community plays an important role in knowledge sharing. The trust and behavior coordination between the knowledge sharing subject and object is the prerequisite to establish effective sharing, exchange and interaction channel.

Trust has been recognized as a key factor affecting knowledge sharing behavior. When individuals trust each other, they are willing to contribute personal information or resource. Trust is important because it could create a necessary atmosphere to sustain social exchange in virtual communities. Trust makes social life predictable, creates community consciousness and makes it easier for people to work together.

From the perspective of social exchange, trust can divided into affective trust and cognitive trust. Affective trust is based on emotional relationship. Cognition trust is based on cognitive reasoning. Trust and behavior coordination between members is the premise to establish an effective channel to knowledge share, which can be enhanced by iterative contract. Bian (1997) concluded the lack of direct relationship and abundant communication among individuals makes it harder for knowledge sharing. In this paper, trust in virtual community is divided into three views: perception of interaction norm, perception of sharing mechanism, perception of interaction level. In these perspectives, trust in virtual communities is built on: good community structure, community management mechanism, members' collaborative relationship. So hypotheses are as follows:

H2. Members' trust tends to affect knowledge sharing willingness in a positive way.

H3. Members' trust influences the knowledge sharing behaviors positively. 


\subsection{Reciprocity}

Reciprocity refers to that both parties expect to gain benefits through exchanges. The exchange behavior is a kind of loss and gain in itself. People can obtain knowledge and information from virtual communities, but they have never been sure that their knowledge will be shared without expectation of a return (Chang \& Chuang, 2011). When people perceive that their social relationship is on an equal footing, they can feel the equality of their interaction. The reason why the knowledge owner is willing to consume his time and energy to share knowledge of the knowledge demander is that he hopes the knowledge demander can convey information to him when the knowledge demander becomes the knowledge owner in the future. In this way, knowledge sharing is achieved.

Reciprocity is the core principle of social exchange theory. In social exchange theory, it suggests that people engaged in social activities and relation tends to give rise to social contribution. Reciprocity is the future earnings expectations after people's contribution of knowledge. Personal cognition of exchange relationships can be decided by the comparison of the input/outcome rate. When people think they are not properly treated, he will reduce input. There are two kinds of social rewards: intrinsic rewards and extrinsic rewards (Blau, 1986). Intrinsic rewards refer to approval, status, love and respect from social relationship. Extrinsic rewards refer to money, goods, invitation, assistance beyond the social interaction. In this paper, reciprocity is divided into two views: reciprocity motivation and reciprocity reward. The reciprocity rewards of knowledge sharing behavior in virtual communities mainly caused by the intrinsic rewards. So hypotheses are as follows:

H4. Members' reciprocity influences knowledge sharing willingness positively.

H5. Members' reciprocity influences knowledge sharing behaviors in a positive way.

\subsection{Altruism}

Though interactive norms dominate social exchange, there is also social responsibility criterion. The social exchange theory argues that altruism is a sort of social exchange. What the altruistic people do is to help others. What they gain is the improvement of their self-value. Altruism in knowledge sharing exists indeed and should be encouraged. Under the influence of altruistic factors, the focus of knowledge sharing is the internal rewards.

In the category of social psychology, altruistic behaviors of individuals are selfless and benefit to others. Some members contribute their knowledge to help others without asking for anything in the process of knowledge sharing. In this paper, altruism is divided into two views: individual efficacy and sharing efficacy. Individual efficacy of altruistic behavior mainly comes from personal self-satisfied, reputation and pleasant experience. This suggests that 
contribution of knowledge in virtual communities will lead to good interaction relationship with other members, which leads to the improvement of sharing efficacy. Accordingly, hypotheses 6 and 7 are as follows:

H6. Members' altruism tends to influence knowledge sharing willingness positively.

H7. Members' altruism influences knowledge sharing behaviors in a positive way.

Social exchange theory is put forwarded to form conceptual research model to study the knowledge sharing behaviors in virtual community in our research. We have proposed seven hypotheses in our study pattern. They represent the impact of trust, altruism and reciprocal factors on the knowledge sharing intention and sharing behaviors in the virtual community. The theoretical model that is proposed in this paper is shown in Fig. 1. In this model, sharing willingness and sharing behavior are endogenous variables, while reciprocity, trust and altruism are potential exogenous variables.

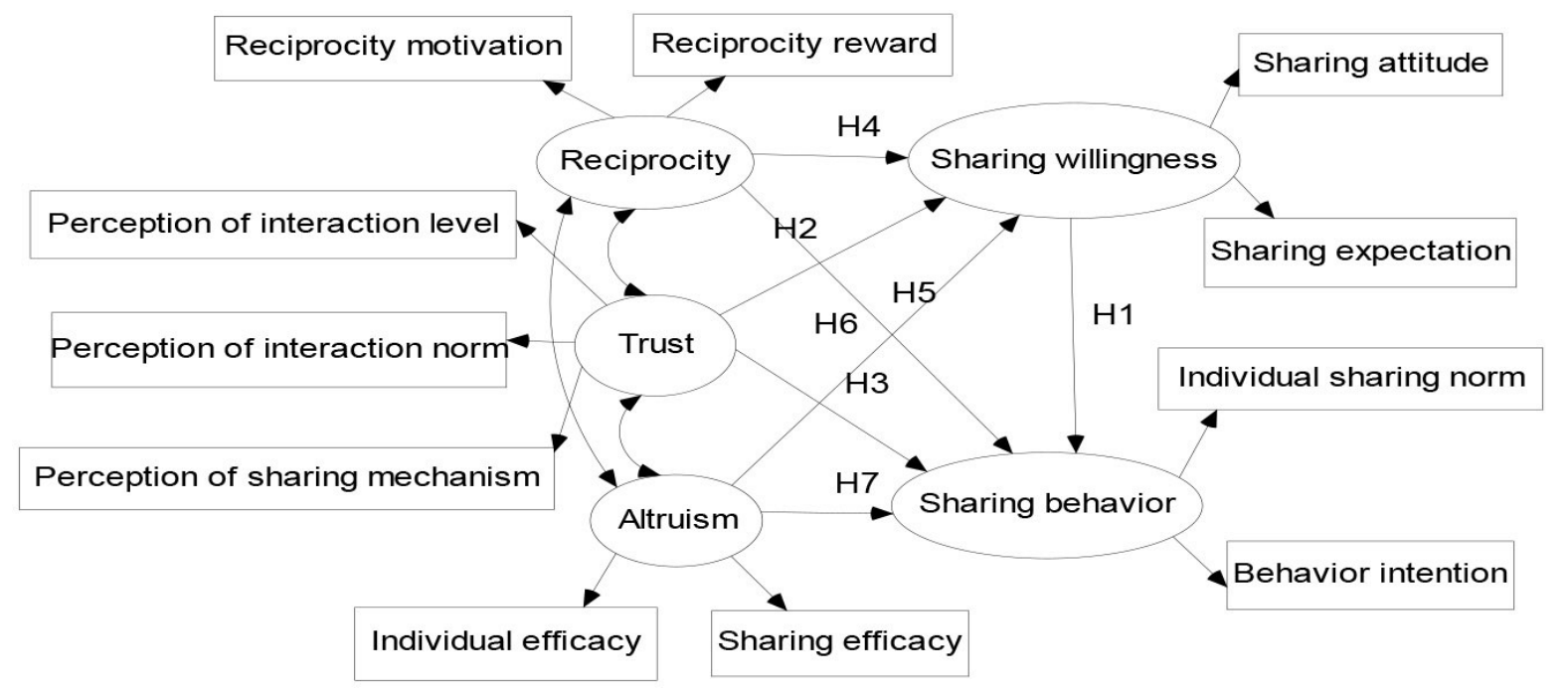

Figures 1. Theoretical model

\section{Survey Administration and Data Analysis}

\subsection{Survey Administration}

To meet the research purpose of this article, most of the items in the questionnaire are derived from previous studies which are concern with knowledge sharing. The questionnaire includes a survey of Background and five scales. Items on reciprocity are adapted from Wasko and Faraj (2005); Items on trust are gained from Chiu et al. (2006); Altruism ideas derive from Chang and Chuang (2011) and Kankanhalli, Tan and Wei (2005); Sharing willingness ideas are 
adapted from Davenport and Prusak (1998); Items on sharing behaviors are adapted from Hsua et al. (2007).

Before the issuing of questionnaires, this paper surveyed 40 students to evaluate the reasonability of the questionnaire design, and made some modification according to advices collected in the pre-survey. The respondents selected by this research are all personnel with the knowledge sharing experiences in the virtual community. Each respondent was expected to fill in the questionnaire about knowledge sharing in the virtual community.

Questionnaires were delivered in both the written and the electronic forms. The respondents of the questionnaire survey were mainly school students. The written questionnaires were delivered to undergraduates, postgraduates and some teachers and workers during the breaks in classroom or by visiting the students' dormitories. The rest of the questionnaires were done through emails. The respondents were people of the author's social relations who have knowledge sharing experience. These respondents account for about $11 \%$ of the total. 240 people who have knowledge sharing experience in virtual community were cordially asked to help on this research. The questionnaire firstly explained research objectivities and ensured the confidentiality. A five-point Likert scale is utilized, from strongly agree (5), agree (4), neutral (3), disagree (2), as well as strongly disagree (1).

\begin{tabular}{|c|c|c|}
\hline Items & Frequency & Proportion \\
\hline $\begin{array}{c}\text { Age (years-old) } \\
\text { Under } 20 \\
20 \sim 25 \\
26 \sim 30 \\
\text { Over } 30\end{array}$ & $\begin{array}{c}120 \\
58 \\
17 \\
6\end{array}$ & $\begin{array}{l}59.7 \% \\
28.9 \% \\
8.5 \% \\
2.9 \%\end{array}$ \\
\hline $\begin{array}{c}\text { Education } \\
\text { Undergraduate } \\
\text { Postgraduate } \\
\text { Doctor }\end{array}$ & $\begin{array}{c}149 \\
37 \\
15\end{array}$ & $\begin{array}{c}74.1 \% \\
18.4 \% \\
7.5 \%\end{array}$ \\
\hline $\begin{array}{l}\text { Gender } \\
\text { Male } \\
\text { Female }\end{array}$ & $\begin{array}{c}96 \\
105\end{array}$ & $\begin{array}{l}47.8 \% \\
52.2 \%\end{array}$ \\
\hline $\begin{array}{c}\text { Member history (year) } \\
\text { Under } 1 \\
1 \sim 2 \\
3 \sim 4 \\
\text { Over } 5\end{array}$ & $\begin{array}{l}27 \\
60 \\
84 \\
30\end{array}$ & $\begin{array}{l}13.4 \% \\
29.9 \% \\
41.8 \% \\
14.9 \%\end{array}$ \\
\hline
\end{tabular}

Table 1. Samples of the Research

When the research is carried out, 221 question forms were gathered excluding 20 invalid forms. The survey gave rise to a total of 201 finished and valid ones for statistical study, registering a validity rate of $83.75 \%$. Considering the demographic features of the interviewees (see Table 1), it can be found that the percentage of males is $47.8 \%$, the percentage of females is $52.2 \%$, and the education background of the respondents is: undergraduates: 
74.1\%, postgraduates: $18.4 \%$; and doctors: $7.5 \%$. The experience of the members in virtual community is: $13.45 \%$ for below one year, $29.9 \%$ for 1 to 2 years, $41.8 \%$ for 3 to 4 years, and $14.9 \%$ for 5 years.

\subsection{Data Analysis and Results}

Wu (2010) suggested the main criteria to test the model are general model fit criteria and internal structure model fit criteria. The internal structure model fit criteria represent the reliability and validity of the measurement model. As shown in Table 2, the convergent validity of the scales is studied utilizing the Cronbach's alpha values. The above are the recommended value of 0.6 , standing for a commonly agreeable degree for exploratory study. The research model use AMOS making confirmatory factor analysis. The assumptions and the paths between the items, and potential construct variables can be studied with the structural model.

The main indices used to test the model are overall model fit index and internal consistency fit index. This paper assessed the internal coherence and discriminant validity of the research model. Two methods are adopted for evaluation of internal coherence. Firstly, convergent validity of the constructs is examined by using the Cronbach's alpha values. In Table 2, all of the values are above the recommended value that is 0.6 (Bagozzi \& Yi, 1988), standing for a commonly agreeable degree for exploratory study. Secondly, we calculated the AVE for each construct. All of the AVE exceeded the guideline of 0.5 (Bagozzi \& Yi, 1988), meaning a good internal consistency.

\begin{tabular}{|c|c|c|}
\hline Latent variables & Measured variables & Cronbach's Alpha \\
\hline \multirow{2}{*}{ Sharing willingness (R1) } & Sharing attitude & 0.842 \\
\cline { 2 - 3 } & Sharing expectation & 0.756 \\
\hline \multirow{2}{*}{ Reciprocity (R2) } & Reciprocity motivation & 0.696 \\
\cline { 2 - 3 } & Reciprocity reward & 0.857 \\
\hline \multirow{2}{*}{ Altruism (R3) } & Individual efficacy & 0.827 \\
\cline { 2 - 3 } & Sharing efficacy & 0.813 \\
\hline \multirow{2}{*}{ Trust (R4) } & Perception of interaction norm. & 0.712 \\
\cline { 2 - 3 } & Perception of sharing mechanism & 0.626 \\
\cline { 2 - 3 } & Perception of interaction level & 0.719 \\
\hline \multirow{2}{*}{ Sharing behavior (R5) } & Individual sharing norm & 0.693 \\
\cline { 2 - 3 }
\end{tabular}

Table 2. Variable and Reliability 


\begin{tabular}{|c|c|c|c|c|c|c|}
\hline Construct & AVE & R1 & R2 & R3 & R4 & R5 \\
\hline R1 & 0.61 & 0.78 & & & & \\
\hline R2 & 0.69 & 0.54 & 0.83 & & & \\
\hline R3 & 0.66 & 0.42 & 0.54 & 0.81 & & \\
\hline R4 & 0.67 & 0.27 & 0.32 & 0.38 & 0.82 & \\
\hline R5 & 0.76 & 0.24 & 0.24 & 0.42 & 0.39 & 0.87 \\
\hline
\end{tabular}

Table 3. AVE and Correlations

This paper used the guideline which is proposed by Fornell and Larcker (1981) to perform an examination of discriminant validity. According to Fornell and Larcker (1981), the AVE root for every construct variable should surpass the correlation between any construct variables. The results of the measurement model analyses can be seen in Table 4. As shown in Tables 3, the AVE root is on the diagonal. The diagonal values surpass the internal construct correlations, providing further evidence that discriminant validity is acceptable.

The research model uses AMOS to make confirmatory factor analysis. The assumptions and paths between the items, and potential variables can be verified using the structural model. The forecast of model can be completed with the usage of maximum likelihood estimate method. Table 4 resents the analysis results of the pattern. In the structural model, $\chi^{2}$ is 45.38, RMSEA is 0.041 , GFI is 0.96 , AGFI is 0.927 , and CFI is 0.936 . The results show that all data are in a reasonable range, which is suitable to the statistics.

\begin{tabular}{|c|c|c|c|c|c|c|}
\hline Model fit index & $\chi^{2}$ & $\mathbf{P}$ & RMSEA & AGFI & GFI & CFI \\
\hline Value & 45.38 & 0.092 & 0.041 & 0.927 & 0.960 & 0.936 \\
\hline Recommended level & -- & $>0.05$ & $<0.05$ & $>0.9$ & $>0.9$ & $>0.9$ \\
\hline
\end{tabular}

Table 4. Goodness-of-fit statistics

\section{Discussion}

On the grounds of the data assumption, the assumed research model is tested by empirically analyses. The finding supports the theoretical pattern for a majority of assumed relationships. Table 5 shows the results of assumption examination by SEM. All the paths included a P-value which is no more than 0.05 . $\mathrm{H} 1$ predicts members' sharing willingness influence the knowledge sharing behaviors in a positive way. The result exhibits a significant path coefficient $(\beta=0.925$, S.E. 0.109 ). Thus hypothesis $\mathrm{H} 1$ was supported. Hypothesis $\mathrm{H} 2$ proposes a link between trust and knowledge sharing willingness. The path was positive and significant $(\beta=0.337$, S.E. $=0.031$ ), suggesting that hypothesis $\mathrm{H} 2$ was supported. The paths from trust to knowledge sharing behaviors can be affirmative and important $(\beta=0.221$, S.E. $=0.041)$. Consequently, 
hypotheses H3 was supported. The path from members' reciprocity to knowledge sharing willingness and knowledge sharing behaviors were positive and significant $(\beta=0.609$, S.E. $=0.024 ; \beta=0.737$, S.E. $=0.073)$. So hypothesis H4 and H5 were supported empirically. The paths from altruism to knowledge sharing willingness is positive $(\beta=0.116$, S.E. $=0.013)$, while a negative path was found between altruism and knowledge sharing behaviors $(\beta=-0.108$, S.E. $=0.021)$. As consequences, assumption $\mathrm{H} 6$ can be verified whereas hypothesis assumption H7 cannot.

\begin{tabular}{|l|l|l|l|l|}
\hline Hypothesis & Estimate & S.E. & P-value & Description \\
\hline Sharing willingness $\rightarrow$ sharing behavior & 0.925 & 0.109 & $<0.05$ & Support \\
\hline Trust $\rightarrow$ sharing willingness & 0.337 & 0.031 & $<0.05$ & Support \\
\hline Trust $\rightarrow$ sharing behavior & 0.221 & 0.041 & $<0.05$ & Support \\
\hline Reciprocity $\rightarrow$ sharing willingness & 0.609 & 0.024 & $<0.05$ & Support \\
\hline Reciprocity $\rightarrow$ sharing behavior & 0.737 & 0.073 & $<0.05$ & Support \\
\hline Altruism $\rightarrow$ sharing willingness & 0.116 & 0.013 & $<0.05$ & Support \\
\hline Altruism $\rightarrow$ sharing behavior & -0.108 & 0.021 & $<0.05$ & Not Support \\
\hline
\end{tabular}

Table 5. Result of hypotheses tests

Contrary to our expectations, the results suggest that members' altruism can not predict knowledge sharing behaviors. Possible reasons for this finding seem that the exchange relationship of knowledge sharing in virtual community has somewhat contingent. Unlike traditional organization, people exchange their knowledge with others through physical interaction. The relationship between members is fragile and not limited by realistic social roles. Therefore, knowledge sharing behaviors are more efficient among members who have close relationship than the other members. On the other side, cultural building in the virtual community influences the virtual social relationship between the members. In different cultural atmosphere, members may have different social behaviors. The teamwork between community members and the altruistic value atmosphere is beneficial for the exchange of various kinds of knowledge and information.

From the results, comparing with trust, reciprocity and altruism, we found that sharing willingness has get a highest factor loading in the latent variables of sharing behavior. The value of social exchanges lies in the maintenance of reputation and long-term relationship. This finding is consistent with Bock's study (Bock et al., 2005). They argued that people contribute their knowledge when their benefits outweigh the expenses from knowledge sharing behaviors. This shows that effective incentive mechanism for social exchange among members should be established to enhance sharing willingness which can promote knowledge sharing behavior in virtual community. In addition, it is important to set up community norms and build personal 
service system, which can improve the attractiveness to members and reduce free-riding behavior in knowledge sharing.

\section{Limitations and further research}

This research aims to research knowledge sharing behaviors in virtual communities from the perspective of social exchange theory. We analyses and do empirical test on the research model to identify the incentive involving in knowledge sharing behaviors. It is important to understand that limitations exist in this research, and further verification and extra study are required. One restriction is that the survey data was collected in a limited area. Further research should expand the source of the survey to improve the general universality of the study. The other limitation is that group analysis is not perfect. Further research should distinguish people's characteristic and incentive of different origin in knowledge sharing behaviors in the cyberspace. The future researches may study the generation mechanism of knowledge sharing behaviors in virtual communities in other perspectives, apart from Social Exchange Theory. For example, the researchers can explore the knowledge sharing process through various psychological and environmental variables.

\section{Acknowledgment}

This research is the achievement of Hubei Province Office of education project.

\section{References}

Bagozzi, R.P., \& Yi, Y. (1988). On the evaluation of structural equation models. Journal of the academy of marketing science, 16(1), 74-94. http://dx.doi.org/10.1007/BF02723327

Bartol, K.M., \& Srivastava, A. (2002). Encouraging knowledge sharing: the role of organizational reward systems. Journal of Leadership and Organizational Studies, 1, 64. http://dx.doi.org/10.1177/107179190200900105

Bian, Y.J. (1997). Bringing strong ties back in indirect ties, network bridges and job searches in China. American Sociological Review, 62. http://dx.doi.org/10.2307/2657311

Blau, P. (1986). Exchange and Power in Social Life. New York: John Wiley \& Sons.

Bock, G., Zmud, R., Kim, Y., \& Lee, J. (2005). Behavioral intention formation in knowledge sharing: examining the roles of extrinsic motivators, social-psychological forces, and organizational climate. MIS Quarterly, 87-111. 
Bock, G.W, \& Kim, Y.G. (2002). Breaking the myths of rewards: An exploratory study of attitudes about knowledge sharing. Information Resources Management Journal, 15(2), 14-21. http://dx.doi.org/10.4018/irmj.2002040102

Brown, J.S., \& Duguid, P. (2001). Knowledge and organization: A social-practice perspective. Organization science, 12(2): 198-213. http://dx.doi.org/10.1287/orsc.12.2.198.10116

Chang, H.H., \& Chuang, S.S. (2011). Social capital and individual motivations on knowledge sharing: Participant involvement as a moderator. Information \& management, 48(1), 9-18. http://dx.doi.org/10.1016/j.im.2010.11.001

Chiu, C.M., Hsu, M.H., \& Wang, E.T.G. (2006). Understanding knowledge sharing in virtual communities: An integration of social capital and social cognitive theories. Decision Support Systems, 42, 1872-1888. http://dx.doi.org/10.1016/j.dss.2006.04.001

Davenport, T.H., \& Prusak, L. (1998). Working Knowledge: How Organizations Manage What They Know. Harvard Business School Press, Boston.

Emerson, R.M. (1976). Social Exchange Theory. Annual Review of Sociology, 2,335-362. http://dx.doi.org/10.1146/annurev.so.02.080176.002003

Fornell, C., \& Larcker, D.F. (1981). Evaluating structural equation models with unobservable variables and measurement error. Journal of Marketing Research, 18(1), 39-50. http://dx.doi.org/10.2307/3151312

Fulk, J., Flanagin, A.J., Kalman, M.E., \& Monge, P.R. (1996). Connective and Communal Public Goods in Interactive Communication Systems. Communication Theory, 6(1), 60-87. http://dx.doi.org/10.1111/j.1468-2885.1996.tb00120.x

Hsu, M.H., Ju, T.L., Yen, C.H., \& Chang, C.M. (2007). Knowledge sharing behavior in virtual communities: The relationship between trust, self-efficacy, and outcome expectations. International Journal Human-Computer Studies, 65(2), 153-169.

http://dx.doi.org/10.1016/j.ijhcs.2006.09.003

Kankanhalli, A., Tan, B.C., \& Wei, K.K. (2005). Contributing knowledge to electronic knowledge repositories: an empirical investigation. MIS quarterly, 113-143.

Kim, Y.G., Yu, S.H., \& Lee, J.H. (2003). Knowledge strategy planning: Methodology and case. Expert Systems with Applications, 24(3), 295-307. http://dx.doi.org/10.1016/S0957-4174(02)00158-6

Koh, J., \& Kim, Y.G. (2004). Knowledge Sharing in Virtual Communities: An e-business Perspective. Expert systems with applications, 26, 155-166. http://dx.doi.org/10.1016/S09574174(03)00116-7 
Wasko, M.M., \& Faraj, S. (2005). Why should I Share? Examining Social Capital and Knowledge Contribution in Electronic Networks of Practice. MIS Quarterly, 29(3), 35-57.

Wu, J.J., \& Tsang, A.S. (2008). Factors affecting members' trust belief and behavior intention in virtual communities. Behavior \& Information Technology, 27(2), 115-125. http://dx.doi.org/10.1080/01449290600961910

Wu, M. (2010). Structural equation modeling-AMOS application. Chongqing university publisher.

Journal of Industrial Engineering and Management, 2015 (www.jiem.org)

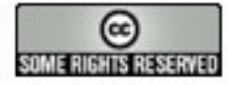

Article's contents are provided on a Attribution-Non Commercial 3.0 Creative commons license. Readers are allowed to copy, distribute and communicate article's contents, provided the author's and Journal of Industrial Engineering and Management's names are included. It must not be used for commercial purposes. To see the complete license contents, please visit http://creativecommons.org/licenses/by-nc/3.0/. 